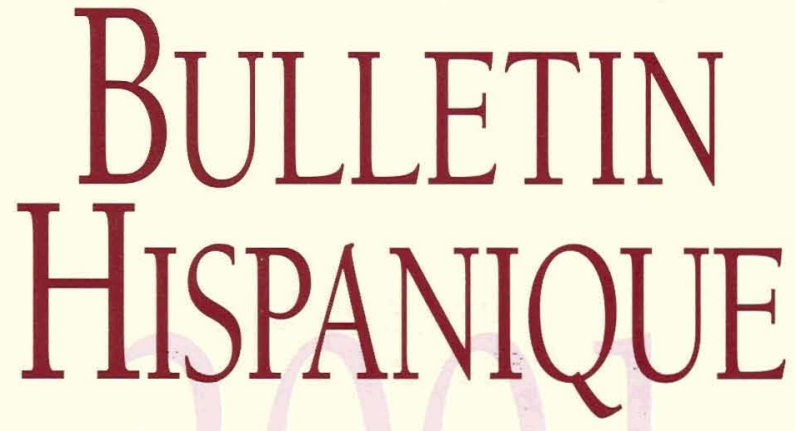

Publié AVEC LE CONCOURS

du Centre National de la Recherche Scientifique

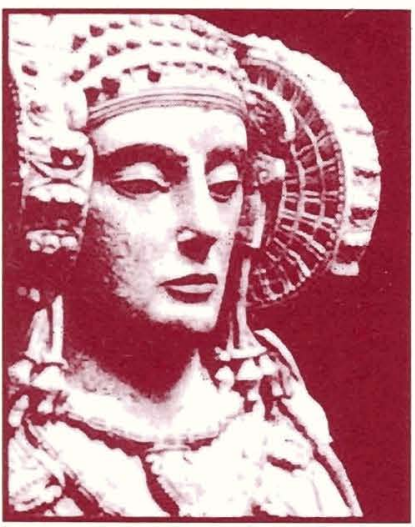

Nº - DÉCEMBRE 2001

Université Michel de Montaigne BORDEAUX 


\title{
Poemas para música de Francisco Manuel de Melo
}

\author{
LOLA JOSA \\ Universidad de Barcelona \\ MARIANO LAMBEA \\ CSIC. Institución Milá y Fontanals
}

Pour que notre travail de recherche interdisciplinaire sur le romancero lyrique espagnol du Siècle d'Or puisse s'inscrire dans les perspectives les plus fécondes, il apparaît indispensable de confronter les sources poético-musicales que nous étudions avec les cuvres poétiques de l'époque. Dans ce but, nous avons mis au point une liste alphabétique des poèmes en castillan des Obras métricas (1665) du poète portugais Francisco Manuel de Melo (1608-1666), en fonction de l'importance attribuée aux indications musicales qui précèdent chaque poème et qui parfois renferment des noms de compositeurs. Nous avons ainsi pu découvrir l'existence de trois poèmes «melodinos» mis en musique dans le Cancionero Poético-Musical Hispánico de Lisboa, dont nous préparons actuellement l'édition. Deux de ces romances lyriques furent mis en musique par les compositeurs Luiz de Christo (1625-1693) et Filipe da Madre de Deus (ca. 1630-in ou après 1688).

Para el óptimo desarrollo de nuestro trabajo de carácter interdisciplinario sobre el romancero lírico español de los Siglos de Oro, es indispensable cotejar las obras poéticas de la época con las fuentes poético-musicales que estudiamos. En este sentido hemos elaborado una relación de poemas en castellano de las Obras métricas (1665) del poeta portugués Francisco Manuel de Melo (1608-1666), basada en la importancia que tienen las indicaciones musicales que preceden a dichos poemas y que, en ocasiones, contienen nombres de compositores. De esta manera hemos podido descubrir tres poemas "melodinos» puestos en música en el Cancionero Poético-Musical Hispánico de Lisboa, cuya edición estamos preparando. Dos de estos romances líricos fueron musicados por los maestros Luiz de Christo (1625-1693) y Filipe da Madre de Deus (ca. 1630-en o después de 1688).

B. Hi., nº 2 - décembre 2001 - p. 427 à 448. 
In order to achieve the best development of our work, which has an interdisciplinary character and talks about the Spanish lyrical ballads from the Golden Age, it is essential to compare the poetical works of this age with the poetic-musical sources that we study. In that way, we have elaborated a list of poems in Spanish from Obras métricas (1665) written by the Portuguese poet Francisco Manuel de Melo (1608-1666). This list is based on the importance of the musical references which precede the poems and which, sometimes, include the names of the composers. In this way, we have been able to discover three "melodinos» poems set to music in the Cancionero Poético-Musical Hispánico de Lisboa whose edition we are preparing. Two of these lyrical ballads were set to music by the masters Luiz de Christo (1625-1693) and Filipe da Madre de Deus (ca. 1630-in or after 1688).

Mots-clés: Romancero lyrique espagnol - Musique et Poésie (Siècle d'or) - Chansonniers poético-musicaux (Siècle d'or) - Melo, Francisco Manuel de (1608-1666) - Cancionero Poético-Musical Hispánico de Lisboa.

$\mathrm{N}$ UESTRO primer propósito, para el presente artículo, era ofrecer el estudio y la edición crítica de tres romances líricos de Francisco Manuel de Melo (1608-1666) ${ }^{1}$, editados por él mismo en sus Obras métricas (1665) ${ }^{2}$, y puestos en música, con importantes variantes poéticas, en el cancionero que

1. El mejor estudio de conjunto que existe hasta el presente sobre Francisco Manuel de Melo es el de J. Estruch i Tobella, Vida y obra de Francisco Manuel de Melo, Barcelona, Universidad de Barcelona, Facultad de Filología (Tesis Doctoral inédita), 1985, a quien debemos, además, numerosos artículos y trabajos sobre el poeta y escritor, y que, con suma amabilidad y entrega, puso a nuestro alcance. Consúltense, entre otros: «La concepción de la poesía en Hospital das letras, de Francisco Manuel de Melo", Quadrant, 6, 1989, p. 5-20; "Tras las huellas de las Soledades. el "Panteón», de F. M. de Melo», en M. García Martín (ed.), Estado actual de los estudios sobre el Siglo de Oro, Salamanca, Ediciones Universidad de Salamanca, 1990, p. 331-338; "Un muestrario de la poesía barroca portuguesa: As segundas três musas, de Francisco Manuel de Melo", Quadrant, 8, 1991, p. 5-32; "Cuarenta sonetos manuscritos de Francisco Manuel de Melo», Criticón, 61, 1994, p. 7-30; "Un poema gongorino (inédito) de Francisco Manuel de Melo", Manojuelo de estudios literarios ofrecidos a José Manuel Blecua Tejeiro, (s. a.), p. 155-168.

2. Sólo vamos a trabajar con los que el poeta editó en sus Obras métricas, León de Francia, Horacio Boessat y George Remeus, MDCLXV. En este libro se hallan reimpresas las Tres Musas del Melodino, halladas por D. Francisco Manuel, Lisboa, Oficina Craesbeeckiana, 1649 (cfr. J. Simón Díaz, Bibliografía de la literatura hispánica, Madrid, Consejo Superior de Investigaciones Científicas, 1984, tomo XIV, p. 545); estas tres musas son: El Harpa de Melpómene, primera musa; La Cítara de Érato, segunda musa; y La Tiorba de Polimnia, tercera musa. 
ahora nos ocupa en su edición: el Cancionero Poético-Musical Hispánico de Lisboa, así titulado por nosotros mismos. Esta importante fuente poéticomusical se conserva en la Biblioteca da Ajuda, ubicada en el Palácio Nacional da Ajuda, en Lisboa. Se le había venido denominando de varias maneras, como, por ejemplo, «Madrigais. Sec. XVI» ${ }^{3}$, "Cancionero Musical Español de Ajuda" "4, "Cancionero de Lisboa" ${ }^{5}$, y, nosotros mismos, cuando sólo conocíamos esta fuente por referencias, la habíamos citado como "Cancionero Musical de Lisboa» ${ }^{6}$ y como "Cancionero Musical de Ajuda» 7 , con el riesgo, en esta última denominación, y al no especificar marco cronológico, de confundirlo con el códice más antiguo de los cancioneros gallego-portugueses, el famoso Cancionero de Ajuda del siglo XIII, que contiene unas 300 canciones de amor de filiación provenzal. En cambio, ahora, con la máxima autoridad que otorga el estudio directo sobre el cancionero y nuestro trabajo interdisciplinario, no dudamos en titularlo como queda dicho, puesto que creemos que es la denominación más correcta y apropiada por hacer referencia explícita al contenido artístico que lo conforma - poesía y música, en igualdad de calidad artística y perfectamente

3. Véase M. A. Machado Santos, Catálogo de música manuscrita, Lisboa, Biblioteca da Ajuda, 1960, vol. III, p. 41. De idéntica manera aparece referenciada esta fuente en la exposición Flores de Música da Biblioteca da Ajuda. Exposiçãa de raridades musicais manuscritas e impressas dos séculos XI a XX, Lisboa, Ministério da Educação Nacional, 1973, p. 10. Es cierto que estas piezas pueden considerarse madrigales desde el punto de vista musical, ya que cualquier forma métrica de contenido poético elevado y delicado puesta en música mediante parámetros de expresividad, técnica y estilo variados, elegantes y equilibrados, cabe en la estética madrigalesca. Sin embargo, no sucede lo mismo desde el punto de vista métrico, puesto que las obras del cancionero que nos ocupa al ser, en su inmensa mayoría, romances líricos con estribillo o romances sin estribillo, no presentan las características básicas del madrigal en cuanto a rima y número de versos heptasílabos y endecasílabos. Por otra parte, la adscripción cronológica al siglo XVI no puede ser del todo cierta, entre otras muchas razones, porque los poemas de Melo que aquí se ponen en música pertenecen al siglo XVII.

4. Véase M. Querol, «Dos nuevos cancioneros polifónicos españoles de la primera mitad del siglo XVII», Anuario Musical, XXVI, 1971, p. 106.

5. Véase J. Etzion, «The spanish polyphonic cancioneros c. 1580 - c. 1650: A survey of literary content and textual concordances", Revista de Musicologia, XI, 1, 1988, p. 66; y también El Cancionero de la Sablonara. Ed. de J. Etzion, London, Tamesis Books, 1996, p. Ixviii.

6. Véase La música y la poesía en cancioneros polifónicos del siglo XVII. I Libro de Tonos Humanos, vol. I. Ed. de M. Lambea (música) y L. Josa (poesía), Monumentos de la Música Española, vol. LX, Barcelona, Consejo Superior de Investigaciones Científicas, 2000, p. 67b.

7. Véase M. Lambea, Incipit de poesía española musicada, Madrid, Sociedad Española de Musicología, 2000, p. 20. 
hermanadas en un solo arte-, a la época y área de influencia cultural y política que lo vio nacer, $y$, por último, a la ciudad en la que se halla.

El primer propósito que mencionábamos más arriba se inició en el mes de enero del año 2001, cuando fuimos expresamente a Lisboa para trabajar, in situ, en la Biblioteca da Ajuda, en busca de los cuatro cuadernos manuscritos que acogen entre sus páginas las 130 composiciones poético-musicales castellanas del siglo XVII que conforman el precioso cancionero. De sus 130 obras, 90 tienen estribillo y 7 presentan coplas. Todas las piezas vienen anónimas tanto en la música como en el texto. La distribución de voces y signaturas en los cuadernos manuscritos es la siguiente:

$\begin{array}{lll}\text { Voz instrumental: } & \text { "Guião a } 4 » & \text { Signatura: } 47-V I-10 . \\ \text { Primera voz: } & \text { "Tiple } 1^{\circ} \text { a } 4 » & \text { Signatura: 47-VI-11. } \\ \text { Segunda voz: } & \text { "Tiple 2० a 4» } & \text { Signatura: 47-VI-12. } \\ \text { Cuarta voz: } & \text { "Tenor a 4» } & \text { Signatura: 47-VI-13. }\end{array}$

A pesar de que ya conocíamos la existencia de este cancionero por la catalogación de Machado Santos ${ }^{8}$, y el trabajo documental, y meramente descriptivo, de Querol ${ }^{9}$, nuestra obligación era examinar a fondo su contenido, sobre todo, por continuar con nuestra labor de edición de los cancioneros españoles polifónicos profanos del siglo XVII, que todavía permanecen inéditos. Rápidamente nos percatamos de la importancia y el valor artístico que poseen esas músicas y poesías. Por otra parte, pudimos observar que, en efecto, se trata de un cancionero polifónico con composiciones a cuatro voces y acompañamiento instrumental. Lamentablemente, esta importante fuente poético-musical se conserva incompleta, ya que falta una de las cuatro voces. Pero, por fortuna, nos enfrentamos a una reconstrucción que no presenta muchas complicaciones, puesto que componer una de las cuatro voces no es tarea insalvable para un musicólogo, sobre todo, si se trata, como así es en la mayoría de estas piezas, de una voz interior, es decir, la segunda o tercera ${ }^{10}$.

En los cancioneros poético-musicales nunca acostumbra a figurar el nombre del poeta. Ésta es una dificultad añadida para el filólogo y un reto

8. M. A. Machado Santos, op. cit., p. 41. En este catálogo todas las piezas del cancionero se hallan entradas por orden alfabético de primeros versos.

9. M. Querol, "Dos nuevos cancioneros polifónicos españoles...", p. 104-111.

10. No se puede precisar de manera genérica qué voz falta en todas las piezas, puesto que hay composiciones en las que falta la segunda voz (Tiple $2^{\circ}$ ) y otras en las que falta la tercera (Alto). 
científico a su labor y preparación. Tampoco es muy normal que aparezcan nombres de compositores en fuentes poéticas - excepción hecha de los pliegos sueltos de villancicos religiosos-; sin embargo, dentro del ámbito de la poesía profana, tenemos dos casos de tonos humanos en los que sí se recogen los nombres de los músicos: en las Letras armónicas puestas en música por los mejores maestros de España de Diego de Nájera y Cegrí (activo a finales del siglo XVII) ${ }^{11}$ y en las Obras métricas del poeta portugués que nos ocupan. Dimos con la pista de Francisco Manuel al observar la disposición de su corpus métrico, dividido en las nueve musas, y éstas, a su vez, antecedidas por el nombre de un instrumento musical diferente ${ }^{12}$ :

El Harpa ${ }^{13}$ de Melpómene, primera musa del Melodino, y primera parte de sus versos. Sonetos (p. 1-76).

La Cítara ${ }^{14}$ de Érato, segunda musa del Melodino, y segunda parte de sus versos. Romances (p. 77-135).

La Tiorba ${ }^{15}$ de Polimnia, tercera musa del Melodino, y tercera parte de sus versos. Metros (p. 136-358).

A Tuba ${ }^{16}$ de Calliope, quarta musa do Mellodino. Rimas. Sonetos (en portugués, p. 1-51 de la segunda numeración).

11. Manuscrito que se conserva en la Biblioteca de The Hispanic Society of America, bajo la signatura MS. B2392. Véase la relación de primeros versos, junto con los nombres de los compositores que aparecen, en A. Rodríguez-Moñino y M. Brey Mariño, Catálogo de los manuscritos poéticos castellanos existentes en la biblioteca de The Hispanic Society of America (siglos XV, XVI y XVII), New York, The Hispanic Society of America, 1965, vol. II, p. 300-303.

12. Queremos facilitar los datos básicos de cada uno de ellos y consideramos suficientes las definiciones que trae el Diccionario de Autoridades (Aut.). En consecuencia, creemos que no hay necesidad de recurrir a tratados musicales de la época, o diccionarios especializados u obras de organología, porque nos darían definiciones excesivamente técnicas que, quizá, no estarían en consonancia con las intenciones, simplemente poéticas y literarias, de Melo.

13. Harpa: «instrumento músico de figura casi triangular, cuyo cuerpo es compuesto de un número de costillas de madera, formando una manera de ataúd que se une por encima con una tabla delgada, hechos en ella algunos agujeros grandes para que salga la voz. [...] Se toca con ambas manos, abrazándose con él por la parte del cuerpo más estrecha» (Aut.).

14. Cítara: «instrumento músico semejante algo a la guitarra, pero más pequeño y redondo» (Aut.).

15. Tiorba: "especie de laúd, algo mayor y con más cuerdas" (Aut.).

16. Tuba: en portugués, en lenguaje poético, "trompeta». Pero, en el siglo XVII, trompeta era "lo mismo que clarín" (Aut.), y éste, "trompa de bronce derecha, que, desde la boca, por donde se toca, hasta el extremo, por donde sale la voz, va igualmente ensanchándose, y el sonido que despide es muy agudo" (Aut.). 
A Çanfonha ${ }^{17}$ de Euterpe, quinta musa do Mellodino. Eglogas e epistolas (en portugués, p. 53-132).

A Viola ${ }^{18}$ de Thalía, seista musa do Melodino. Obras (en portugés, p. 133285).

La Lira ${ }^{19}$ de Clío, sétima musa del Melodino. Epigramas (p. 1-52 de la tercera numeración). 84).

La Avena ${ }^{20}$ de Tersicore, octava musa del Melodino. Tonos y romances (p. 53-

La Fistula ${ }^{21}$ de Urania, novena musa del Melodino. Asuntos a la reina, nuestra señora (p. 85-176).

Los tres poemas «melodinos» puestos en música en el Cancionero PoéticoMusical Hispánico de Lisboa son los siguientes (incluimos la numeración que tendrá cada pieza en nuestra futura edición $-\mathrm{y}$ que coincide con la que trae el índice en el original, en los ff. $1 \mathrm{r}-2 \mathrm{r}$ y ff. $112 \mathrm{r}-112 \mathrm{v}$ del cuaderno $47-\mathrm{VI}-$ 10 - y la foliación moderna en tampón que consta en los cuatro cuadernos manuscritos):

9. «El basalisco encarnado»: ff. 10v-11r en el cuaderno 47-VI-10 y ff. 9v10r en los cuadernos 47-VI-11, 47-VI-12 y 47-VI-13 (Lámina 1).

13. «Ave real peregrina»: ff. $14 \mathrm{v}-15 \mathrm{r}$ en el cuaderno $47-\mathrm{VI}-10$ y ff. $13 \mathrm{v}-14 \mathrm{r}$ en los cuadernos 47-VI-11, 47-VI-12 y 47-VI-13 (Lámina 2).

128. "Rayaba el sol por las cumbres»: ff. 109v-110r en el cuaderno 47-VI10 y ff. $108 \mathrm{v}$ y $109 \mathrm{r}$ en los cuadernos $47-\mathrm{VI}-11$, 47-VI-12 y 47-VI-13 (Lámina 3).

Al tiempo que identificábamos la autoría de estos tres romances musicados en el cancionero lisboeta, nos llenaba de igual sorpresa comprobar cómo algunos de los romances, tonos, letrillas, madrigales, etc., de las Obras métricas, ya no sólo iban precedidos de sustanciosos epígrafes que referían el asunto convertido en materia poética, sino que, asimismo, iban acompañados de in-

17. Çanfonha: zampoña. "Instrumento rústico-pastoril a modo de flauta, o compuesto de muchas flautas" (Aut.).

18. Viola: "parecido en todo al violón, aunque mayor, y tiene por lo regular seis cuerdas y ocho trastes que proceden por semitonos" (Aut.).

19. Lira: «el que hoy se llama 'lyra' es muy semejante al laúd, del cual sólo se diferencia en tener algunas cuerdas más, y tocarse con un arquillo pequeño" (Aut.).

20. Avena: «lo mismo que flauta» (Aut.).

21. Fístula: "cierto género de instrumento músico que, regularmente, es de caña, y, animado con el viento, causa variedad de sones» (Aut.). 
dicaciones como "para música», "puesto en música», "para cantarse», "para cantarse al uso", u otras expresiones similares. En definitiva, que la edición de 1665 de los poemas «melodinos» venía a apuntalar toda nuestra teoría que, en torno al romancero lírico - mal llamado hasta ahora "nuevo» o "artístico»-, habíamos desarrollado a propósito de nuestra edición del primer volumen del Libro de Tonos Humanos ${ }^{22}$. Ello nos hizo considerar que, antes de dar prioridad a la edición crítica de los tres romances del poeta portugués, junto con los comentarios pertinentes a sus versiones musicadas del Cancionero Poético-Musical Hispánico de Lisboa, debíamos ofrecer a la comunidad científica el índice de poemas de Francisco Manuel de Melo que habían sido concebidos para ser realzados por la música. A la hora de confeccionarlo, hemos escogido sólo aquellos que ofrecían en su epígrafe una referencia explícita de que habían sido puestos en música o se habían escrito, expresamente, para ser musicados. Debemos decir, no sin mucho pesar, que hemos excluido del índice romances que, a buen seguro, por su temática, por sus personajes..., habrían sido concebidos para ser cantados, pero, a falta de una referencia evidente, no nos ha quedado otra opción que silenciarlos: el rigor con que hemos concebido el índice así lo requería.

¿La importancia de este índice? Se trata de una prueba más de lo que venimos defendiendo en nuestros trabajos sobre la necesidad interdisciplinaria en la investigación del romancero lírico español del Seiscientos, tal y como no se cansó de proponer José F. Montesinos, de quien nos sentimos seguidores. El lector podrá comprobar por sí mismo -que es de lo que se trata- la riqueza de indicaciones musicales, incluidos nombres de compositores, que el propio Melo prodigó en la edición de su poesía. ¿Cuántas pruebas más necesitamos para que el musicólogo cuente siempre, como necesidad ineludible, con un filólogo en la edición de un cancionero poéticomusical, y el filólogo, a su vez, piense en la música inmediatamente leído un romance del siglo XVII?

\section{ACERCA DE LOS COMPOSITORES}

Será conveniente ahora ofrecer algunas referencias sobre los músicos que, junto a sus composiciones, aparecen citados en las Obras métricas de Melo. Sólo nos referiremos a su producción sobre textos profanos, obviando sus

22. Véase La música y la poesía en cancioneros polifónicos del siglo XVII..., remitimos a la "Introducción» general, al estudio de "La poesía» y al de "La música», p. 11-18, 19-36 y 6595 , respectivamente. 
composiciones sacras con texto en latín o sus villancicos religiosos. Muchas obras sacras y religiosas de varios de estos compositores se custodiaban en la biblioteca de João IV (1604-1656, rey de Portugal entre 1640-1656), pero, por desgracia, se perdieron en el terremoto que asoló Lisboa en $1755^{23}$.

- Luiz de Christo (1625-1693) ${ }^{24}$.

Sabemos de este compositor portugués que, en 1642, era carmelita calzado en el monasterio de su orden en Lisboa, y, en 1660, desempeñaba el cargo de organista en la catedral lisbonense. Fue favorecido en la corte de Alfonso VI (1643-1683, rey de Portugal entre 1656-1683). Puso música a cuatro poemas de Melo; dos con indicación específica al inicio del poema: «Lucir con las sombras, Licis» y «Temer la hermosura, Juana»; y dos con indicación procedente de un poema inmediatamente anterior: "Con envidias de la gala» $\mathrm{y}$ «El basalisco encarnado».

- Filipe da Cruz (ca. 1603-ca. 1668) ${ }^{25}$.

Compositor portugués que residió parte de su vida en España. Fue maestro de música en la Casa de la Misericordia en Lisboa. En 1641 fue nombrado cantor en la capilla real española. Compuso una misa en la que declaró de manera velada su obediencia al rey João IV de Portugal, quien, en 1656 , le nombró maestro de la capilla real portuguesa. Se conservan dos composiciones suyas en el Libro de Tonos Humanos: «Es, en el mar de la corte» ${ }^{26}$ y «No cantéis, dulce ruiseñor» ${ }^{27}$. Puso música al poema de Melo «Si apagar quieres, Lucía».

- Esteval de Faria.

Nada hemos podido averiguar de este compositor que musicó el tono de Melo «Unos ojos sin color».

23. Véase el catálogo que se ha conservado de esa riquísima biblioteca musical en la edición de M. de Sampaio Ribeiro, Primeira parte do index da Livraria de música de El-Rei D. João IV. (Reprodução facsimilada da edição de 1649), Lisboa, Academia Portuguesa da História, 1967. Consúltese también el útil trabajo de A. Luis Iglesias, Villancicos en romance del Index de D. Ioão IV, rey de Portugal Valladolid, La Palma, [1993].

24. Véase R. Stevenson, "Christo, Luiz de», The New Grove Dictionary of Music and Musicians. S. Sadie (ed.), London, Macmillan, 1980, vol. 4, p. 374.

25. Véase R. Stevenson, "Cruz, Filipe da», ibidem, vol. 5, p. 75.

26. Madrid, Biblioteca Nacional, M. 1262, ff. 8v-10r [14v-16r]. Véase la edición moderna en La música y la poesía en cancioneros polifónicos del siglo XVII..., p. 41 para la poesía y $137-140$ para la música.

27. Madrid, Biblioteca Nacional, M. 1262, ff. 166v-168r [172v-174r]. Véase la edición moderna en Música barroca española. Vol. I. Polifonía profana (Cancioneros españoles del siglo XVII). Ed. de M. Querol Gavaldá, Monumentos de la Música Española, vol. XXXII, Barcelona, Consejo Superior de Investigaciones Científicas, 1970, p. 91-94. 
- Miguel de Herrera.

Tampoco tenemos noticia de este compositor que puso música a dos poemas de Melo; uno con indicación específica al inicio del poema: "Vengo a daros buenas reinas»; y otro con indicación procedente de un poema inmediatamente anterior: «Apeóse el firmamento».

- Antonio de I.

No hemos podido obtener ninguna referencia sobre el nombre, tan fragmentario, de este músico que aparece como autor de la música de la poesía de Melo «La buena dicha os empiezo».

- António Marques Lésbio (1639-1709) ${ }^{28}$.

Compositor y escritor portugués. El maestro João Soares Rebelo, del que hablaremos más adelante, al observar una de sus composiciones tempranas, predijo que el joven músico llegaría a ser uno de los mejores contrapuntistas portugueses. Entre 1665 y 1668 publicó varios poemas en español y portugués en las actas de la Academia dos Singulares, alguna de cuyas sesiones había presidido. En 1668 llegó a ser maestro de los músicos de la cámara real. Fue un acérrimo partidario de Pedro II (1648-1706, rey de Portugal entre 1683-1706). En 1679 fue nombrado maestro de los niños cantores de la capilla real, en 1692 conservador de la biblioteca real de música y en 1698 maestro de coro real. Melo lo cita como autor de la música de dos tonos suyos: «En esta obscura noche» y «iOh, cuán bien despliega al aire...!».

- Filipe da Madre de Deus (ca. 1630-en o después de 1688) ${ }^{29}$.

Compositor portugués que residió durante bastante tiempo en España. Entre 1660 y 1667 fue maestro de música de la cámara real de Alfonso VI en Lisboa. De regreso a Sevilla dirigió la actividad musical de la Iglesia Carmelitana de San José hasta 1688. Adquirió notable fama en Sevilla como compositor de tonos humanos en los que se apreciaba su capacidad improvisatoria y su estilo ágil y avanzado para su época. João IV, el famoso rey músico, que prefería un estilo más sobrio y serio para la composición, le acusó de plagiar al maestro Manuel Correa. También sabemos que a Madre de Deus se le encargó la composición de seis obras festivas para conmemorar las celebraciones que tuvieron lugar en Sevilla en honor de Mariana de Austria, segunda esposa de Felipe IV. Es el compositor más citado en las obras de Melo, con nueve composiciones, todas con indicación específica de su nombre: "iAh, señores, señores cazadores,...!", "Cuatro o seis torres que

28. Véase R. Stevenson, «Lésbio, António Marques», ibidem, vol. 10, p. 687-688.

29. Véase R. Stevenson, «Madre de Deus, Filipe da», ibídem, vol. 11, p. 457. 
fueron», «Desengáñate, morena», «En los floridos albores», «iHala, al palenque, galanes...!», «Madama, vuestros ojuelos», "¿Quién es aquella Diana...?», «Rayaba el sol por las cumbres» y «Yo soy ciego y no veo nada».

- Marcos Soares Pereira (ca. 1595-1655) ${ }^{30}$.

Compositor portugués, hermano mayor del maestro João Soares Rebelo. En 1629 sucedió a Roberto Tornar como maestro de capilla en Vila Viçosa. Cuando el Duque de Braganza llegó al trono como João IV, le acompañó a Lisboa donde fue nombrado maestro de coro, cargo que desempeñó hasta su muerte. Puso música a tres tonos "melodinos»: "¿Quién es aquel de lo pardo...?», "Si a ser madrina vas, Juana» y "Vuelen nuestras señorías".

- João o João Lourenço Soares Rebelo (1610-1661) ${ }^{31}$.

Compositor portugués, hermano de Marcos Soares Pereira, a quien se unió en el coro que mantenía Dom Teodósio II, padre de João IV, en Vila Viçosa. A los veinte años, en sus primeras obras, ya mostraba su inclinación por la composición en estilo policoral para grandes masas corales. En 1646, el rey João IV le otorgó un título nobiliario de su casa real, y, en 1649, el propio monarca le dedicó su opúsculo Defensa de la musica moderna ${ }^{32}$, alabando la excelencia de sus numerosas composiciones. Sin duda, Rebelo es el compositor más importante de cuantos cita Melo en sus obras. Su prestigio, así como los favores que el rey le dispensó, no pasarían desapercibidos al poeta, que no dudó en calificarlo de «insigne maestro real», al frente de su tono «Convidó la primavera».

- Gaspar de los Reyes.

El único dato que hemos podido averiguar de este músico procede de la biblioteca del rey João IV, donde se conservaban varios de sus villancicos, algunos con el nombre de Gaspar dos Reys ${ }^{33}$. Melo lo cita como autor de la música de tres de sus poemas: «Apostara yo que había», «Blanca de los cabos negros» $\mathrm{y}$ «En vano andáis, pensamiento».

30. Véase R. Stevenson, "Pereira, Marcos Soares», ibídem, vol. 14, p. 365.

31. Véase R. Stevenson, «Rebelo, João Soares o João Lourenço», ibídem, vol. 15, p. 640641.

32. João IV, Defensa de la musica moderna contra la errada opinion del obispo Cyrilo Franco. Ed. facsímil de M. de Sampayo Ribeiro, Coimbra, Universidade de Coimbra, 1965, p. 1-2.

33. Véase A. Luis Iglesias, op. cit., p. 172. 
ÍNDICE DE PRIMEROS VERSOS ${ }^{34}$

$\begin{array}{ll}\text { Abreviaturas } & \\ A T & \text { La Avena de Tersícore } \\ C E & \text { La Citara de Érato } \\ F U & \text { La Fístula de Urania } \\ T P & \text { La Tiorba de Polimnia }\end{array}$

A la fuente va del olmo

«Idilio músico, noche de S. Juan. Romance [vario] ${ }^{35} \mathrm{XX}$ » (CE, p. 94b96b).

¿Adónde te partes, dulce mi enemigo,...?

«Madrigales para música al modo italiano. Huida. Madrigal XII» (FU, p. 120).

¡Ah, señores, señores cazadores,...! ${ }^{36}$

"Corte en la aldea. Enceladilla real a las damas de Palacio. Puesta en música por el P. M. F. Felipe de la M[adre] de D[ios]. Tono XIV [XV]» ${ }^{37}$ (AT, p. 62-63b).

Allá se va, no sé adónde

"Para cantarse al uso. Romance [entretenido] XXXIII» (CE, p. 111b$113 b)$.

34. Hemos modernizado la ortografía -siempre y cuando el valor fonético no se viera alterado-, y la puntuación. Entre paréntesis, a continuación de la abreviatura del título del libro, se indica el número de la página seguido de la columna, en el caso de que ésta tenga que especificarse.

35. Indicamos entre corchetes esta aclaración, puesto que en La Cítara de Érato aparece como adjetivo de todos los romances recogidos en esa sección. Entiéndase, pues, de este modo, con todos aquellos adjetivos encerrados entre corchetes.

36. "Coplas en celebración de las damas que se hallaron en esta jornada con sus proprios nombres: "Traviesamente agradable», «La Azucena de Lencastre», "QQué bien la Rosa de Castro...!", "Aquel Clavel de Mendoza», "El jazmín de Portugal», "Tan criminal como hermoso», "De esa ilustre, mas villana», "Quien tus castigos aguarda», "Cada flor más delincuentemm.

37. Entre corchetes ofrecemos la numeración correcta de todos los tonos de La Cítara de Erato, puesto que, a partir del IX, la numeración es errónea. 
Apeóse el firmamento ${ }^{38}$

«Para cantarse a la mesma serenísima reina, después de un sarao real en que danzaron los reyes, puesto en música del proprio maestro ${ }^{39}$. Tono II» ( $A T$, p. 54).

Apostara yo que había ${ }^{40}$

«Dama que se perdió entre la muchedumbre. Puesto en música del maestro Gaspar de los Reyes. Tono XVIII [XIX]» (AT, p. 66).

Aura fresca, aura volante

"Cancionetas balatas al modo italiano. El aurora. Cancioneta XIII» (FU, p. 121).

Ave real peregrina ${ }^{41}$

«Belleza y luto. Romance [heroico] VI» (CE, p. 81b-82b).

¡Ay, Dios!, ¿en qué ha de parar...?

«Para cantarse. Letrilla LIX» (TP, p. 250).

Blanca de los cabos negros 42

«Dama de cabos negros. Puesto en música por el maestro Gaspar de los Reyes. Tono XVI [XVII]» (AT, p. 65).

Con envidias de la gala

"Lutos hermosos, puesto en música por el proprio maestro ${ }^{43}$. Tono VI» (AT, p. 56b-57a).

Convidó la primavera ${ }^{44}$

«La primavera. Puesto en música por el insigne maestro real Juan Suares Rebelo. Tono XV [XVI]»(AT, p. 63b-64).

38. Estribillo: «¿Quién oyó, quién oyó, señores...?».

39. Se refiere a Miguel de Herrera (véase «Vengo a daros buenas reinas»).

40. Estribillo: «Marica, en tus perdiciones».

41. Este es uno de los tres romances de Melo, mencionados anteriormente, que hemos descubierto en el Cancionero Poético-Musical Hispánico de Lisboa. Por ello lo incluimos en este índice, pese a que en su epígrafe no aparezca indicación musical alguna.

42. Estribillo: «¡Ay, cómo lloro! Mas, ¡ay, cómo canto!».

43. Se refiere al P. M. F. Luis de Cristo (véase «Lucir con las sombras, Licis»).

44. Coplas: «Zagalejos destos prados». 
Cuatro o seis torres que fueron ${ }^{45}$

«Ruina argumentosa. Puesto en música por el P. M. F. Felipe de la M[adre] de D[ios]. Tono XIII [XIV]» (AT, p. 60b-61).

Desengánate, morena ${ }^{46}$

"El retrato de una dama hecho de los naipes, con música del P. M. F. Felipe de la M[adre] de D[ios]. Tono III» (AT, p. 54b-55a).

El basalisco encarnado ${ }^{47}$

"La terrible hermosura. Puesto en música por el mesmo maestro ${ }^{48}$. Tono XII $[\mathrm{XIII}] »(A T, \mathrm{p} .60)$.

En esta obscura noche ${ }^{49}$

"Saüdades desesperadas. Puesto en música por el maestro Antonio Marques. Tono $\mathrm{X}[\mathrm{XI}] »(A T, \mathrm{p} .59)$.

En los floridos albores ${ }^{50}$

«Años y amores vida. Puesto en música del P. M. F. Felipe de la M[adre] de $\mathrm{D}[$ ios]. Tono IX" (AT, p. 58a).

En vano andáis, pensamiento ${ }^{51}$

«Desengaños últimos amorosos. Puesto en música por el maestro Gaspar de los Reyos [=Reyes]. Tono VII» $(A T$, p. 57a).

¡Hala, al palenque, galanes...! ${ }^{52}$

«La travesura atapada. Puesto en música por el P. M. F. Felipe de la $\mathrm{M}$ [adre] de $\mathrm{D}[\mathrm{ios}]$. Tono IX [X]» (AT, p. 58b-59a).

Juno soy, Paris, atiende

"El juicio de Paris, prevenido a la loa cantada de una real comedia. Romance IX» (AT, p. 79b-80).

45. Estribillo: «La gloria deste mundo».

46. Estribillo: «Juega, juega, morena».

47. Estribillo: «Recoger, recoger aprisa...!?.

48. Se refiere al P. M. F. Luis de Cristo (véase "Temer la hermosura, Juana»).

49. Estribillo: «Mas, jay, tristes porfias!».

50. Estribillo: «Zagales, ¿quién tiene oído...?».

51. Estribillo: «iTened, tened, suspiros...!).

52. Coplas: «¿Quién habrá, pues, que resista...?». 
La buena dicha os empiezo 53

«En fiesta de Natividad de la Virgen compuesto por el P. M. F. Antonio de I. Tono XXVI [XXVII]» (AT, p. 70a-71).

La contienda de méritos sublime

"Coro de ninfas prevenido a la música del Juicio de Paris. Silva IV» (FU, p. 95-97).

La novilla del jurado

«Para cantarse. Romance [entretenido] XXXV» (CE, p. 115).

Lucir con las sombras, Licis 54

«Lutos y lágrimas de la divina Licis. Puesto en música por el P. M. F. Luis de Cristo. Tono V» (AT, p. 56).

Llorosa en la blanca arena

«Idilio músico. Romance [vario] XVI» (CE, p. 91a-92).

Madama, vuestros ojuelos 55

«La linda francesa. Puesto en música del P. M. F. Felipe de la M[adre] de $\mathrm{D}[\mathrm{ios}]$. Tono IV» $(A T$, p. 55b).

Nadie burle con amor

"Cancionetas balatas al modo italiano. Amor fingido, vuelto verdadero. Cancioneta XIV» (FU, p. 122-123).

¡Oh, cuán bien despliega al aire...! 56

«Despedido sin esperanza. Puesto en música por el maestro Antonio Marques. Tono VIII» $(A T$, p. $57 \mathrm{~b})$.

¡Oh, qué despacio que vienes...! ${ }^{57}$

"Al Nacimiento, para cantarse. Romance [sacro] XXVI" $(C E$, p. 101a102a).

53. Copla: «Mas, si Maricas que alegra».

54. Estribillo: «iHuyan, huyan los otros...!».

55. Estribillo: «Nadie se canse».

56. Estribillo: «Id con Dios para otra esfera».

57. Estribillo: «Mas, jay, qué suena...!». 
¡Oigan, oigan, qué belígero...!

"Para cantarse al uso. Romance [entretenido] XXXIV» (CE, p. 113b115a).

Pesia tal, con la Aldoncilla

"Para cantarse. Romance [entretenido] XXXI» (CE, p. 109).

Pues he llegado, amiga, a tu presencia

"Madrigales para música al modo italiano. La bienvenida. Madrigal XI" (FU, p. 119-120).

¿Qué es esto, qué misterio, qué armonía...?

«Prólogo heroico para una comedia en música o drama cantada. Bajará desde el aire en una nube un gallardo pastor que represente la figura de Paris. Estancias III» (FU, p. 92-95).

Quien dijo que la ausencia causa olvido ${ }^{58}$

«Madrigales para música al modo italiano. Ausencia. Madrigal X» (FU, p. 119).

¿Quién es aquel de lo pardo...? 59

"Jacarilla de devoción en la fiesta de san Francisco. Puesta en música por el maestro Marcos Suares. Tono XXV [XXVI]» (AT, p. 70).

¿Quién es aquella Diana...? ${ }^{60}$

«Belleza no conocida. Puesto en música por el P. M. F. Felipe de la $\mathrm{M}$ [adre] de $\mathrm{D}[\mathrm{ios}]$. Tono XIX $[\mathrm{XX}] »(A T$, p. 66b-67a).

58. Con el verso "Quien dice que el ausencia causa olvido" comienza un soneto que consta en J. Vásquez Villancicos y canciones, Juan de León, Osuna, 1551, (véase el texto completo en J. B. Gallardo, Ensayo de una biblioteca española de libros raros y curiosos, Madrid, Imprenta y fundición de Manuel Tello, 1889, tomo cuarto, col. 923, y la edición moderna en J. Vásquez, Villancicos i canciones. Ed. de E. Russell, Madison, A-R Editions, INC., 1995). También consta un poema que empieza con este mismo verso en la comedia Cuerdos hay que parecen locos de Juan de Zabaleta (apud J. de Matos Fragoso, Comedias escogidas XXXIII, Ioseph Fernandez de Buendia, 1670), así como en el Manuscrito Novena (véase L. K. Stein, Songs of Mortals, Dialogues of the Gods, Oxford, Clarendon Press, 1993, p. 395).

59. Estribillo: "Jacarilla, jacarilla".

60. Estribillo: «iZagalejo, que te despeñas...!». 
Rayaba el sol por las cumbres ${ }^{61}$

«Novela desdichada. Puesto en música por el P. M. F. Felipe de la M[adre] de D[ios]. Tono XVII [XVIII]» (AT, p. 65b-66a).

Si a ser madrina vas, Juana ${ }^{62}$

"La bella Madrina. Puesto en música por el maestro Marcos Suares. Tono XXI $[\mathrm{XXII}] »(A T$, p. 67b-68a).

Si apagar quieres, Lucía ${ }^{63}$

«Dama en noche de luminarias. Puesto en música por el maestro Felipe de la Cruz. Tono XXIV [XXV]» (AT, p. 69b-70a).

Sobre la concha de Venus

«Para música. Romance [heroico] I» (CE, p. 77-78b).

Temer la hermosura, Juana ${ }^{64}$

"Justificación de temores. Puesto en música por el P. M. F. Luis de Cristo. Tono XI [XII]» (AT, p. 59b-60a).

Unos ojos sin color ${ }^{65}$

«Celebrando la raridad de unos ojos. Puesto en música por el maestro Esteval de Faria. Tono XX [XXI]» (AT, p. 67).

¡Váyanse todas Maricas...!

"Celebrando el nombre, la hermosura y la música de una dama. Romance XII» ${ }^{66}$ (AT, p. 83).

Vengo a daros buenas reinas

"Escribióse de Buenas Pascoas a la Majestad de la Reina de Inglaterra, para que se cantase en su cámara, y fue la música del maestro Miguel de Herrera. Tono I» (AT, p. 53-54a).

61. Estribillo: «Ay, pobre peregrino...!».

62. Estribillo: «iLlegar, llegar...!»».

63. Estribillo: «No pretendas, Lucía».

64. Estribillo: «Mas, jay quién oyó...!».

65. Estribillo: «¿Con quién habéis de reñir...?».

66. Mantenemos este romance porque llevamos comprobado, en nuestros trabajos del romancero lírico español, que "la dama cantora" es uno de los temas favoritos a la hora de escoger romances para ser puestos en música. 
Vuelen nuestras señorías ${ }^{67}$

«Habiendo llegado dos damas a su portería para subir a palacio, se hallaba dormido el portero, a quien llamaron en vano; y por celebrar esta acción se escribió este tono. Puesto en música por el maestro Marcos Suárez. Tono XXII $[\mathrm{XXIII}] »(A T, \mathrm{p} .68)$.

Ya la ovejuela perdida 68

"Música a una ausente. Romance [amoroso] XLVII» (CE, p. 128).

Ya sale el alba en Oriente

"Cancionetas balatas al modo italiano. El alba y Filis. Cancioneta XV» (FU, p. 123-124).

Yo soy ciego y no veo nada ${ }^{69}$

«Pidiéronse las coplas que se siguen para continuar un tono que a la primera copla se había hecho por el P. M. F. Felipe de la M[adre] de D[ios]. Tono XXIII [XXIV]» (AT, p. 69).

\section{BIBLIOGRAFÍA}

El Cancionero de la Sablonara. Ed. de Judith Etzion, London, Tamesis Books, 1996. Estruch i Tobella, Joan, Vida y obra de Francisco Manuel de Melo, Barcelona, Universidad de Barcelona, Facultad de Filología (Tesis Doctoral inédita), 1985.

-, "La concepción de la poesía en Hospital das letras, de Francisco Manuel de Melo», Quadrant, 6, 1989, p. 5-20.

-, "Tras las huellas de las Soledades. el "Panteón", de F. M. de Melo», en Manuel García MARTín (ed.), Estado actual de los estudios sobre el Siglo de Oro, Salamanca, Ediciones Universidad de Salamanca, 1990, p. 331-338.

-, "Un muestrario de la poesía barroca portuguesa: As segundas três musas, de Francisco Manuel de Melo», Quadrant, 8, 1991, p. 5-32.

-, "Cuarenta sonetos manuscritos de Francisco Manuel de Melo», Criticón, 61, 1994, p. 7-30.

-, "Un poema gongorino (inédito) de Francisco Manuel de Melo", Manojuelo de estudios literarios ofrecidos a José Manuel Blecua Tejeiro, (s. a.), p. 155-168.

67. Estribillo: «Llamen de espacio, señoras». Copla: «No les cause maravilla».

68. Es prácticamente inimaginable que este romance, con semejante epígrafe, no haya sido concebido para ser cantado; por ello lo mantenemos.

69. Estribillo: "Ciego soy, mas no tanto». 
ETzION, Judith, «The spanish polyphonic cancioneros c. 1580 - c. 1650: A survey of literary content and textual concordances", Revista de Musicología, XI, 1, 1988, p. 65-107.

Flores de Música da Biblioteca da Ajuda. Exposição de raridades musicais manuscritas e impressas dos séculos XI a XX, Lisboa, Ministério da Educação Nacional, 1973.

Gallardo, Bartolomé José, Ensayo de una biblioteca española de libros raros y curiosos, Madrid, Imprenta y fundición de Manuel Tello, 1863-1889, 4 tomos.

JAMmeS, Robert, "Elementos burlescos en las Soledades de Góngora», Edad de Oro, II, 1983, p. 99-117.

JOĀO IV, Defensa de la musica moderna contra la errada opinion del obispo Cyrilo Franco. Ed. de Mário de Sampayo Ribeiro, Coimbra, Universidade de Coimbra, 1965.

JosA, Lola y LAmBEA, Mariano, "Música y Poesía en el Libro de Tonos Humanos (1655-1656). Necesidad de la metodología interdisciplinaria para su edición", en Begoña Lolo (ed.), Actas del V Congreso de la Sociedad Española de Musicología, Madrid, Sociedad Española de Musicología (en prensa).

-, «El juego entre arte poético y arte musical en el romancero lírico español de los Siglos de Oro", en Actas del XIV Congreso de la Asociación Internacional de Hispanistas, (en prensa).

La música y la poesía en cancioneros polifónicos del siglo XVII. I Libro de Tonos Humanos, vol. I. Ed. de Mariano LAMBEA (música) y Lola JosA (poesía), Monumentos de la Música Española, vol. LX, Barcelona, Consejo Superior de Investigaciones Científicas, 2000.

LAMBEA, Mariano, Incipit de poesía española musicada, Madrid, Sociedad Española de Musicología, 2000.

Luis IgLesias, Alejandro, Villancicos en romance del Index de D. Ioão $I V$, rey de Portugal, Valladolid, La Palma, [1993].

Machado Santos, Mariana Amélia, Catálogo de música manuscrita, Lisboa, Biblioteca da Ajuda, 1958-1967/68, IX vols.

Matos Fragoso, Juan de, Comedias escogidas XXXIII, Ioseph Fernandez de Buendia, 1670.

[Melo], Francisco Manuel de, Tres Musas del Melodino, Lisboa, Oficina Craesbeeckiana, 1649.

-, Obras Métricas, León de Francia, Horacio Boessat y George Remeus, 1665.

Música barroca española. Vol. I. Polifonia profana (Cancioneros españoles del siglo XVII). Ed. de Miguel Querol GavaldÁ, Monumentos de la Música Española, vol. XXXII, Barcelona, Consejo Superior de Investigaciones Científicas, 1970.

NÁJERA y CEGRÍ, Diego de, Letras armónicas puestas en música por los mejores maestros de España (MS. B2392 de The Hispanic Society of America). 
Querol, Miguel, "Dos nuevos cancioneros polifónicos españoles de la primera mitad del siglo XVII», Anuario Musical, XXVI, 1971, p. 93-111.

Rodríguez-Moñino, Antonio y Brey Mariño, María, Catálogo de los manuscritos poéticos castellanos existentes en la biblioteca de The Hispanic Society of America (siglos XV, XVI y XVII), New York, The Hispanic Society of America, 1965, 2 vols.

Sampaio Ribeiro, Mário de, Primeira parte do index da Livraria de música de El-Rei D. João IV. (Reprodução facsimilada da edição de 1649), Lisboa, Academia Portuguesa da História, 1967.

Simón Díez, José, Bibliografia de la literatura hispánica, Madrid, Consejo Superior de Investigaciones Científicas, 1984, XVI tomos.

SteIn, Louise K., Songs of Mortals, Dialogues of the Gods, Oxford, Clarendon Press, 1993.

Stevenson, Robert, "Christo, Luiz de», "Cruz, Filipe da», "Lésbio, António Marques", "Madre de Deus, Filipe da», "Pereira, Marcos Soares" y «Rebelo, João Soares o João Lourenço", en Stanley SADIE (ed.), The New Grove Dictionary of Music and Musicians, London, Macmillan, 1980, 20 vols.

VÁsQUEZ, Juan, Villancicos y canciones, Juan de León, Osuna, 1551.

-, Villancicos i canciones. Ed. de Eleanor Russell, Madison, A-R Editions, INC., 1995 . 
Láminas

ลे

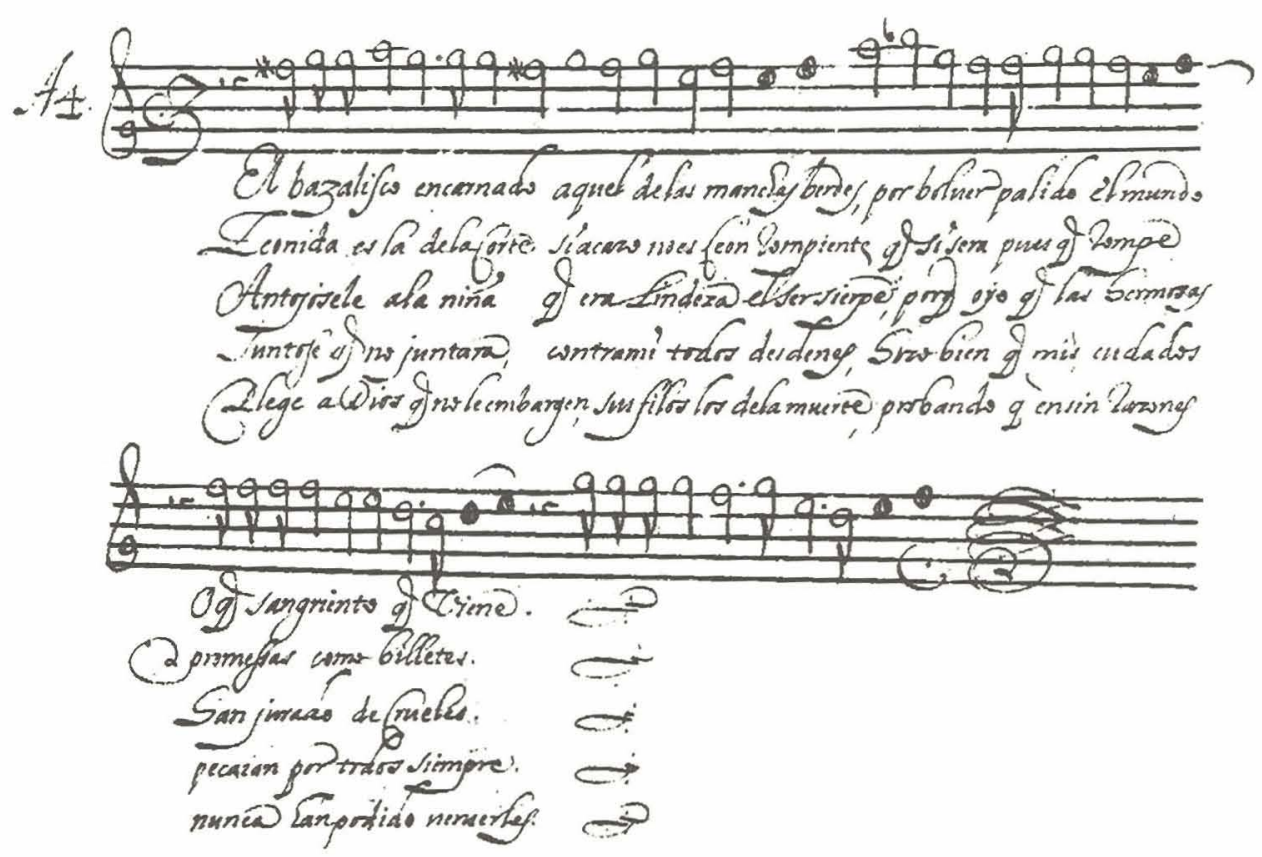

\section{Lámina 1}

9. «El basalisco encarnado». Cancionero Poético-Musical Hispánico de Lisboa.

Lisboa, Biblioteca da Ajuda, ms. 47-VI-11 (f. 9v), Tiple 1.

Texto: Anónimo [=Francisco Manuel de Melo, Obras métricas, La Avena de Tersicore, p. 60].

Música: Anónimo [=Luiz de Christo]. 

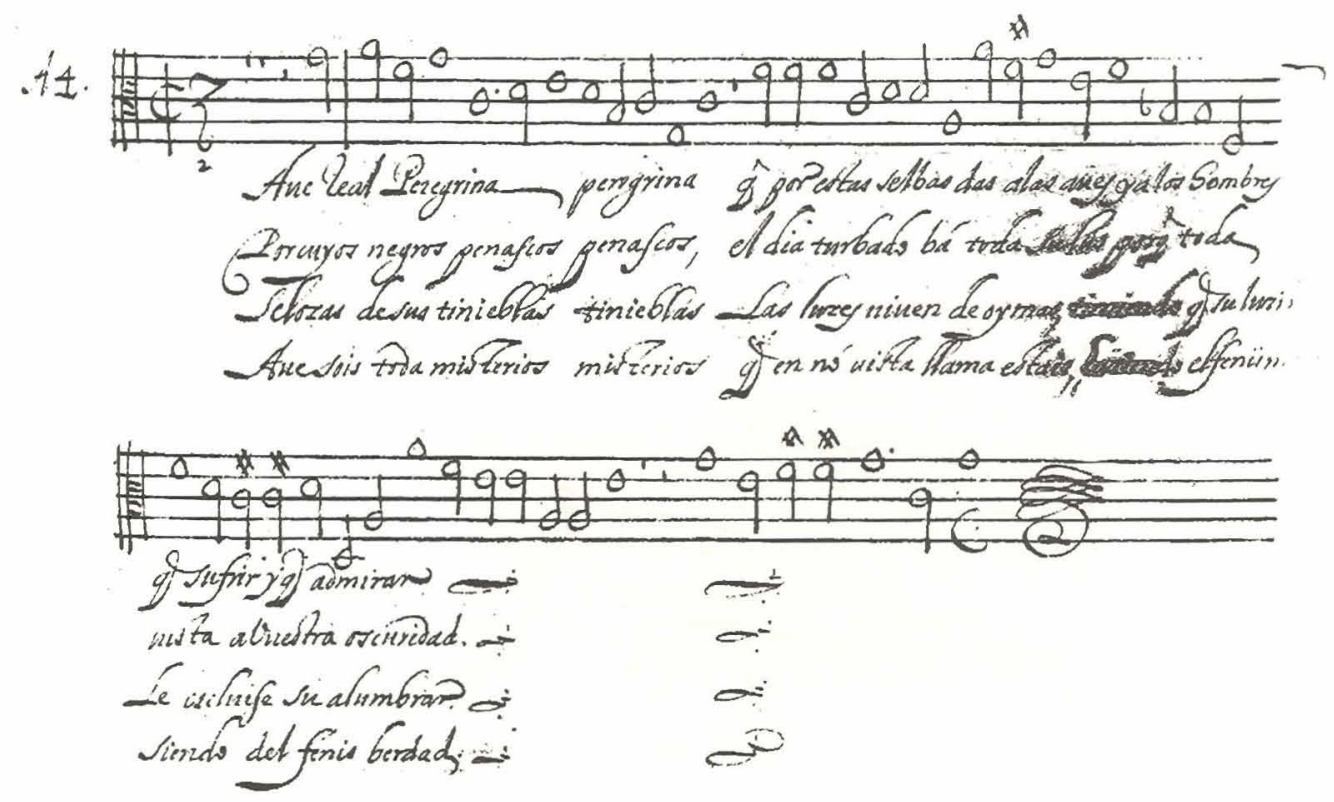

Lámina 2

13. «Ave real peregrina». Cancionero Poético-Musical Hispánico de Lisboa.

Lisboa, Biblioteca da Ajuda, ms. 47-VI-13 (f. 13v), Tenor.

Texto: Anónimo [=Francisco Manuel de Melo, Obras métricas, La Cítara de Erato, p. 81-82].

Música: Anónimo. 

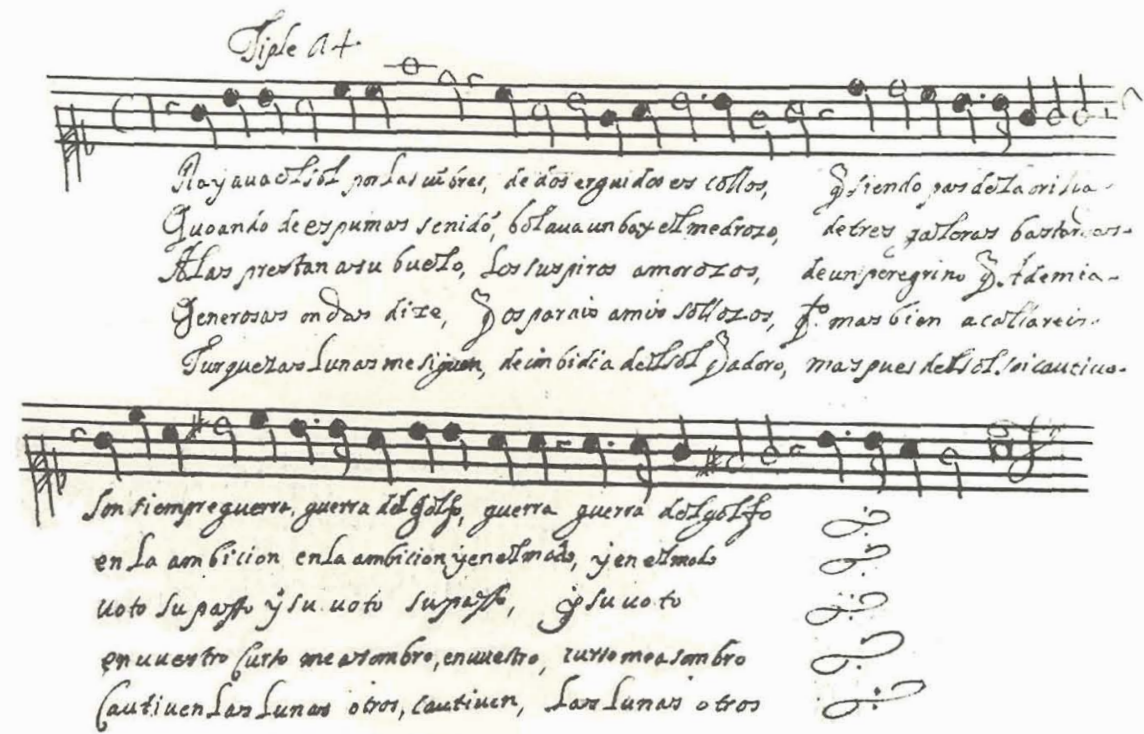

Lámina 3

128. «Rayaba el sol por las cumbres». Cancionero Poético-Musical Hispánico de Lisboa. Lisboa, Biblioteca da Ajuda, ms. 47-VI-12 (f. 108v), Tiple 2.

Texto: Anónimo [=Francisco Manuel de Melo, Obras métricas, La Avena de Tersicore, p. 65-66].

Música: Anónimo [=Filipe da Madre de Deus]. 